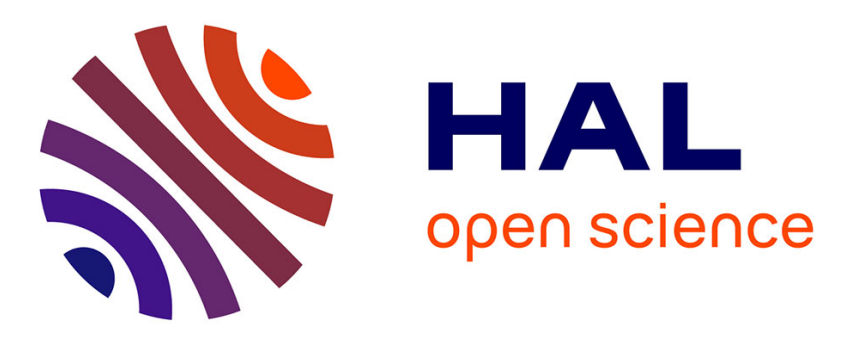

\title{
Wide Spectrum of Desmosomal Mutations in Danish Arrhythmogenic Right Ventricular Cardiomyopathy Patients
}

\author{
Alex Hørby Christensen, Marianne Benn, Henning Bundgaard, Anne \\ Tybjærg-Hansen, Stig Haunso, Jesper Hastrup Svendsen
}

\section{To cite this version:}

Alex Hørby Christensen, Marianne Benn, Henning Bundgaard, Anne Tybjærg-Hansen, Stig Haunso, et al.. Wide Spectrum of Desmosomal Mutations in Danish Arrhythmogenic Right Ventricular Cardiomyopathy Patients. Journal of Medical Genetics, 2010, 47 (11), pp.736. 10.1136/jmg.2010.077891 . hal-00568506

\section{HAL Id: hal-00568506 https://hal.science/hal-00568506}

Submitted on 23 Feb 2011

HAL is a multi-disciplinary open access archive for the deposit and dissemination of scientific research documents, whether they are published or not. The documents may come from teaching and research institutions in France or abroad, or from public or private research centers.
L'archive ouverte pluridisciplinaire $\mathbf{H A L}$, est destinée au dépôt et à la diffusion de documents scientifiques de niveau recherche, publiés ou non, émanant des établissements d'enseignement et de recherche français ou étrangers, des laboratoires publics ou privés. 


\section{Wide Spectrum of Desmosomal Mutations in Danish Arrhythmogenic Right Ventricular Cardiomyopathy Patients}

Alex Hørby Christensen ${ }^{\mathrm{a}, \mathrm{b}}, \mathrm{MD}$; Marianne Benn ${ }^{\mathrm{c}}, \mathrm{MD}, \mathrm{PhD}$; Henning Bundgaard ${ }^{\mathrm{a}}$, MD, DMSc;

Anne Tybjærg-Hansen ${ }^{\mathrm{d}}$, MD, DMSc; Stig Haunso ${ }^{\mathrm{a}, \mathrm{b}, \mathrm{e}, \mathrm{f}}$, MD, DMSc; and Jesper Hastrup

Svendsen ${ }^{\mathrm{a}, \mathrm{b}, \mathrm{f}}, \mathrm{MD}, \mathrm{DMSc}$

${ }^{\mathrm{a}}$ Department of Cardiology, Rigshospitalet, Copenhagen University Hospital

${ }^{\mathrm{b}}$ The Danish National Research Foundation Centre for Cardiac Arrhythmia, Denmark

${ }^{c}$ Department of Clinical Biochemistry, Herlev Hospital, Copenhagen University Hospital

${ }^{\mathrm{d}}$ Department of Clinical Biochemistry, Rigshospitalet, Copenhagen University Hospital

${ }^{\mathrm{e}}$ Laboratory for Molecular Cardiology, Rigshospitalet, Copenhagen University Hospital

${ }^{\mathrm{f}}$ Department of Surgery and Medicine, Faculty of Health Sciences, University of Copenhagen

Corresponding author:

Alex Hørby Christensen, MD

Department of Cardiology, Section 2142, Rigshospitalet

Blegdamsvej 9, DK-2100 Copenhagen, Denmark

Tel +45 35452142, Fax ++45 35383186, Email: alexhc@ dadlnet.dk

Article word count: 2956; Abstract word count: 249; Tables: 3 (+3 in Data Supplement); Figures: 3

Keywords: ARVC; Genetics; Desmosome; Cardiomyopathy 


\section{$\underline{\text { Abstract }}$}

Background: Arrhythmogenic right ventricular cardiomyopathy (ARVC) is a lethal condition characterized by ventricular tachyarrhythmias, right- and/or left ventricular involvement and fibrofatty infiltrations in the myocardium. The disease has been associated with mutations in genes encoding desmosomal proteins.

Objective: To thoroughly evaluating an ARVC cohort for desmosomal mutations and large genomic rearrangements and characterized the phenotype associated with double mutation carrier status.

Methods: Sixty-five unrelated patients (55 fulfilling current criteria and 10 borderline cases) were screened for mutations in all known desmosome genes (DSC2, DSG2, DSP, JUP, PKP2) and $T G F b 3$. Presence of genomic rearrangements was assessed by multiplex ligation-dependent probe amplification.

Results: The screening identified 19 different mutations: two mutations in $D S G 2$, four in $D S C 2$, two in DSP (one heterozygous; one homozygous), four in JUP (one patient compound heterozygous) and seven in PKP2. No genomic rearrangements or mutations in $T G F b 3$ were identified. Ten of the mutations were novel. Seven families carried more than one mutation. Clinical evaluation of these families showed a variable phenotype associated with the double mutation carrier status. The homozygous desmoplakin mutation (DSP p.G2056R+p.G2056R) carrier came from a consanguious Danish family and had left ventricular involvement, palmar keratoderma and curly hair consistent with a Carvajal-like syndrome.

Conclusions: Thirty-three percent of patients in this Danish ARVC cohort carried desmosomal mutations with a surprisingly wide mutation spectrum. A substantial proportion of patients carried more than one mutation. Our study supports comprehensive desmosomal mutation screening beyond the first encountered mutation, while routine screening for genomic rearrangements does not seem indicated. 


\section{$\underline{\text { Introduction }}$}

Arrhythomogenic right ventricular cardiomyopathy/dysplasia (ARVC; MIM\# 107970) is an inherited cardiomyopathy characterized by ventricular arrhythmias, sudden cardiac death, right and/or left ventricular involvement, and fibrofatty infiltrations in the myocardium. A clinical diagnosis is made according to published Task Force criteria. ${ }^{12}$ The original criteria ${ }^{1}$ were published in 1994, followed by modified, more sensitive, criteria for first degree relatives in $2002 .^{3}$ Recently, revised Task Force criteria were published ${ }^{2}$ and these include a number of changes: quantification of histology and right ventricular size, novel electrocardiographic features, genetic testing, and several other parameters are now part of the diagnostic criteria.

Seven genes have so far been associated with the disease. Five of these genes encode desmosomal proteins: desmocollin-2 (DSC2; MIM\# 610476) ${ }^{45}$, desmoglein-2 (DSG2; MIM\# $610193)^{6-9}$, desmoplakin $\left(D S P\right.$; MIM\# 607450) ${ }^{1011}$, plakoglobin $\left(J U P ;\right.$ MIM\# 611528) ${ }^{12}$, and

plakophilin-2 (PKP2; MIM\# 609040) ${ }^{14-16}$. The non-desmosomal gene, transforming growth factor beta-3 (TGFb3; MIM\# 107970) ${ }^{17}$, has also been suggested to be involved in the pathogenesis of ARVC. Recently, a gene of unknown function, TMEM43 (MIM\# 604400), was found causative in ARVC5. ${ }^{18}$ The most common form of inheritance is autosomal dominant with variable penetrance and phenotypic expression. In general, the dominantly inherited forms have an isolated cardiac phenotype while the recessive forms also have variable degrees of hair and skin abnormalities. Homozygous mutations in $D S P^{19-21}$ and $J U P^{12}$ have been reported in two cardiocutaneus syndromes named Carvajal Syndrome (MIM\# 605676) and Naxos disease (MIM\# 601214), respectively.

This study is an extension of our previous work investigating the prevalence of $P K P 2$ mutations in Denmark. ${ }^{16}$ First, we aimed systematically at screening all known desmosome genes without excluding known mutation carriers from further analysis. Secondly, we aimed at clinically evaluating family members in families carrying more than one mutation. And finally, we wished to evaluate the contribution of genomic rearrangements to the pathogenesis of ARVC. 


\section{$\underline{\text { Methods }}$}

\section{$\underline{\text { Study population }}$}

The study population comprised a total of 65 unrelated, white individuals. Fifty-five (32 men) patients fulfilled ARVC 1994 Task Force criteria and ten patients (six men) had some ARVC characteristics but did not fulfil the criteria. All patients were identified at a tertiary referral center, Rigshospitalet, Copenhagen University Hospital. The patients were diagnosed in the period 19932008. The clinical characteristics of all index patients are summarized in table 1 . Initial clinical evaluation of family members routinely consisted of physical examination, 12-lead ECG, signalaveraged ECG, transthoracic echocardiography, 48-hour Holter monitoring, and MRI.

The study was approved by the local ethics committee (KF01-152/04), followed the Helsinki Declaration II, and all participants gave written informed consent prior to inclusion.

\section{$\underline{\text { Genetic analyses }}$}

For all living patients genomic DNA was extracted from whole blood using standard techniques. For deceased patients DNA was extracted from paraffin-embedded tissue (individual III:1, Family G and the proband, Family J) or Guthrie card (individual III:4, Family A). Polymerase chain reaction (PCR) amplification of all exons and flanking introns of the DSC2, DSG2, DSP, JUP, $P K P 2$, and $T G F b 3$ genes was performed using standard protocols and PCR fragments were bidirectionally sequenced on an ABI Prism 3730 Analyzer (Applied Biosystems, USA). PCR primers are listed in supplementary table 1. Some fragments were pre-screened using Denaturing High Performance Liquid Chromatography (dHPLC) (Transgenomic, USA) or a LightScanner System (Idaho Technology, USA). Samples pre-screened with dHPLC were mixed with wild type PCR product to enable detection of homozygous variants. DNA extracted from tissue or Guthrie card was amplified and sequenced without any pre-screening. The following reference sequences 
were used: DSC2 (NM_024422/NM_004949), DSG2 (NM_001943), DSP (NM_004415), JUP (NM_002230), PKP2 (NM_004572) and TGFb3 (NM_003229).

Presence of large genomic insertions and deletions was evaluated with a Multiplex Ligation-dependent Probe Amplification (MLPA) Salsa P168 ARVC kit (MRC-Holland, the Netherlands). The kit has probes for DSP, JUP, PKP2, RYR2 and TGFb3. The analyses were performed in accordance with the supplier's protocol, which consisted of four steps: 1) denaturation of DNA and annealing of MLPA probes, 2) ligation, 3) multiplex PCR reaction with universal primers and 4) fragment analysis using capillary electrophoresis.

For all identified mutations at least 650 self-reported healthy, ethnically matched control individuals were screened using Taqman assays (Applied Biosystems, USA) or a LightScanner System.

A mutation was defined as a sequence variant absent in at least 1300 control chromosomes, and affecting one or more conserved nucleotides/residues, or introducing a change in amino acid polarity in a functionally important protein domain. All other sequence changes were referred to as variants. For clarity, only patients who carried at least one mutation were included in diagnostic yield percentages.

\section{$\underline{\text { Statistical analysis }}$}

For comparisons of frequencies of relevant mutations in the patient and control population Fisher's exact two-sided probability tests were used. A p-value $<0.05$ was considered significant. 


\section{$\underline{\text { Results }}$}

\section{Genetic findings}

Eighteen different heterozygous and one homozygous mutation were identified. The mutations occurred in 18 patients fulfilling Task Force criteria. No mutations were found in the borderline group. The mutations identified (table 2) consisted of two in DSG2 (p.T335A, p.E1020AfsX18), four in DSC2 (p.E2K, p.G150A, p.S824L, c.2508+5G>A), two in DSP (c.939+1G>A, p.G2056R+p.G2056R), four in $J U P$ (p.S225L, p.V407I, p.T427M, p.V603L) and seven in $P K P 2$ (previously reported ${ }^{16}$ ). No genomic rearrangements or mutations in TGFb3 were identified. Ten of the mutations were novel. All were absent in a minimum of 650 controls. Six rare variants (DSC2 p.A897KfsX4, DSG2 p.V56M, DSG2 p.V920G, DSP p.C81Y, $P K P 2$ p.D26N, $P K P 2$ p.S140F) occurred in both the patient and control populations. As these variants may contribute to the pathogenesis of ARVC they are mentioned where appropriate. Sequence alignments, in silico analysis, and complete listing of all identified non-synonymous variants are provided in supplementary table 2 and 3. Six families (Families A-F) were digenic mutation carriers, one family compound heterozygous for two plakoglobin mutations (Family G), one family had a homozygous desmoplakin mutation (Family H), and nine families (Families I-L and five families only carrying PKP2 mutations not presented) had a single mutation.

\section{Desmocollin-2}

Four mutations were identified in $D S C 2$. The $D S C 2$ p.E2K mutation affects the second residue in the signal peptide which is cleaved of before insertion into the plasma membrane. The patient carrying the $D S C 2$ p.E2K mutation also carried the $P K P 2$ p.S140F variant (Family D). Two other identified mutations, $D S C 2$ p.G150A and $D S C 2$ p.S824L, both affect highly conserved residues in functionally important parts of the protein. The DSC2 p.G150A mutation co-occurred with the JUP p.S225L (Family A) mutation and the DSC2 p.S824L mutation carrier (Family E) also had the 
$P K P 2$ p.D26N variant. The DSC2 c. $2508+5 \mathrm{G}>$ A splice site mutation (Family I) affects a highly conserved nucleotide in the splice donor site of intron 15 . One proband and one borderline patient carried the reported DSC2 p.A897KfsX4 (c.2687_2688insGA) variant. However, this variant was also present in the control population (two out of 65 patients versus 22 out of 650 controls, $\mathrm{p}=1.0$ ).

\section{Desmoglein-2}

Two mutations were identified in DSG2. One missense mutation (DSG2 p.T335A, Family J)

affecting a highly conserved residue and one out-of-frame deletion (DSG2 p.E1020AfsX18, Family K). One proband and one borderline patient carried the reported DSG2 p.V56M (c.166G>A) and DSG2 p.V920G (c.2759T>G) variants, respectively. These variants were also present in the control population $(1 / 65$ vs. $4 / 650, \mathrm{p}=0.38 ; 1 / 65$ vs. $3 / 650, \mathrm{p}=0.32)$.

\section{Desmoplakin}

Two mutations were identified in DSP. The $D S P$ c.939+1G>A mutation (Family L) disrupts the conserved splice donor site of intron 7 and the homozygous DSP p.G2056R mutation (Family H) affects the highly conserved domain A of the C-terminal part of the protein. One patient (Family C) carried the DSP p.C81Y (c.242G>A) variant. This patient also carried the $P K P 2$ c.2146-2A>T splice site mutation. The DSP p.C81Y variant was present in two out of the 1400 controls screened for this variant $(1 / 65$ vs. $2 / 1400, \mathrm{p}=0.13)$

\section{$\underline{\text { Plakoglobin }}$}

Five mutations in $J U P$ were identified in four patients. All mutations affect highly conserved residues in the armadillo repeat domains. The JUP p.S225L mutation occurred in two unrelated patients, of which one came from a family (Family A) with two other mutations resulting in two different digenic carrier statuses within the same family (JUP p.S225L+PKP2 p.S329EfsX24 and $J U P$ p.S225L+DSC2 p.G150A, respectively). The other JUP p.S225L mutation occurred in a family (Family B) also carrying the PKP2 p.R79X mutation. The mother of a sudden cardiac death 
victim carried two plakoglobin mutations (JUP p.T427M and JUP p.V603L, Family G). The JUP p.V407I mutation carrier (Family F) also had the $P K P 2$ p.D26N variant.

\section{$\underline{\text { Transforming growth factor beta-3 }}$}

No mutations were found in the coding sequence, flanking introns, 5' untranslated region or 500 base pairs upstream of the TGFb3 gene. Two novel polymorphisms (c.*739C>T and c.*831G>A) were found in the 3' untranslated region.

\section{Large genomic rearrangements}

All patients had normal MLPA profiles excluding large genomic insertions and deletions in the DSP, JUP, PKP2, RYR2 and TGFb3 genes.

\section{Clinical findings}

The clinical features of the mutation carriers are summarized in table 3.

In family A (figure 1A), the proband was diagnosed with ARVC at age 18 years prior to her sudden death. The patient's first-degree relatives were evaluated without abnormal findings. Seven years later her 16 year old sister unfortunately died and autopsy showed fibrofatty infiltrations in the myocardium. All family members were re-evaluated and the mother and father, an uncle and two aunts fulfilled criteria for ARVC. Genetic screening revealed a truncating PKP2 mutation (PKP2 p.S329EfsX24) on the maternal side and two different missense mutations on the paternal side (JUP p.S225L and DSC2 p.G150A). All mutations individually segregated with disease. Individual III:4 carried both the fathers and mothers' mutations. Individual II:8, who had a different digenic carrier status (DSC2 p.G150A and JUP p.S225L), had significantly left ventricular involvement (ejection fraction of 30\%). Her son (individual III:6) carried the same two mutations, but had a positive signal-averaged ECG as the only abnormal diagnostic finding at the age of 33 years. An ECG, microscopy photo and an electropherogram from the family are shown in figure $2 \mathrm{~A}-\mathrm{C}$. 
In Family B (figure 1B), the proband had symptom onset at the age of 24 years and was diagnosed with ARVC. His father and brother also had features of ARVC. All family members had normal left ventricular function and there was no history of sudden cardiac death. At the time of diagnosis the proband had documented ventricular tachyarrhythmias, but for the past 11 years of follow-up he has not received ICD-therapy. His father (individual I:1), currently aged 75 years, has not had any ARVC-related symptoms for 20 years. Genetic screening identified two mutations (PKP2 p.R79X and JUP p.S225L). The proband and his father were digenic carriers and the brother only carried the $P K P 2$ p.R79X mutation.

In Family C (figure 1C) the proband had syncopes and ventricular tachycardia and was diagnosed with ARVC. Family evaluation showed that his younger brother (individual II:3) fulfilled Task Force Criteria. His older brother (individual II:4) also had some ARVC characteristics. Both the probands daughters (individual III:1 and III:2) were phenotypically normal. Genetic screening identified one splice site mutation (PKP2 c.2146-2A>T) and one rare variant (DSP p.C $81 \mathrm{Y})$ in the proband, but only the $P K P 2$ mutation in the clinically affected younger brother. One of the daughters carried the DSP p.C81Y variant.

In Families D, E and F (figures 1D-F) all evaluated family members were phenotypically normal and carried none of the probands mutations. 
In Family G (figure 1G) the proband died suddenly aged 31 years and autopsy revealed fibrofatty infiltrations in the myocardium. Clinical evaluation of the mildly symptomatic mother showed premature ventricular contractions, but otherwise normal clinical findings. Her brother and son (individuals II:3 and III:2) were asymptomatic but had some diagnostic features of ARVC. Genetic screening showed that the proband was JUP p.T427M mutation carrier, the mother was compound plakoglobin mutation carrier (JUP p.T427M and JUP p.V603L) and the mother's brother and her sons were JUP p.V603L mutation carriers. The two mutations segregated with disease individually.

In Family H (figure 3A-D) the proband had symptom onset at the age of 35 years and was diagnosed with ARVC with left ventricular involvement. In addition, palmar keratoderma was noted (figure 3C). No significant plantar skin manifestations or woolly hair were seen. His mother died driving a moped aged 35 years and his father died of cancer aged 78 years. The mother and father were cousins. None of the probands three children had any cardiac symptoms. The proband carried a homozygous DSP p.G2056R mutation and his parents and children were obligate heterozygous mutation carriers. His brother and sister declined clinical and genetic evaluation. 


\section{$\underline{\text { Discussion }}$}

On the basis of our present results combined with our previous $P K P 2$ screening we conclude that $33 \%$ of patients in this Danish ARVC cohort had mutations in desmosomal genes. Our cohort had a surprisingly wide mutation spectrum with a high frequency of JUP and DSC2 mutations. Previous studies have shown $10-43 \%$ PKP2 mutations $^{14-1622}, 0-12 \%$ DSG2 mutations ${ }^{6-9} 2324,1-16 \%$ DSP mutations $^{61124}$ and 0-5\% DSC2 mutations ${ }^{482324}$. Only three dominant mutations in JUP have

previously been described. ${ }^{132425}$ A single report has associated mutations in $T G F b 3$ with ARVC1 ${ }^{17}$, but mutations have not been described in other populations. However, most previous studies have excluded patients after the first identified mutation.

In six families $(11 \%)$ digenic mutation carriers were identified where at least one of the mutations were absent in the control population. In Families A, B and $\mathrm{G}$ the individual mutations segregated with the disease and were individually regarded as pathogenic. In family A the digenic mutation carriers had a severe phenotype with sudden cardiac death and left ventricular involvement. In contrast, the digenic carriers in family B and G had a mild phenotype with minimal arrhythmia, no left ventricular involvement or sudden cardiac death. Two recent papers suggested a gene dosage effect with patients carrying more than one mutation having a more severe phenotype. ${ }^{8}$ ${ }^{26}$ Our data partially support these findings although the phenotypic variation is large. In Family C the disease segregated with one of the mutations (PKP2 c.2146-2A>T) suggesting that the rare variant (DSP p.C81Y) is not necessary for the development of the ARVC phenotype. Whether the identified rare variants also present in our control population are benign or have a diseasemodifying effect is unknown. In other inherited cardiac arrhythmia syndromes polymorphisms can modify the phenotype. ${ }^{27}$

One patient from a consanguinous Danish family (Family $\mathrm{H}$ ) was a homozygous DSP mutation carrier. Homozygous mutations have been reported for all five desmosomal genes. Except for the homozygous $D S G 2$ and $P K P 2$ mutation carriers all have had variable degrees of hair and 
skin abnormalities. A single report has shown a homozygous DSP missense mutation (p.G2375R+p.G2375R), located in the B domain of the C-terminal part of the protein, as cause of Carvajal Syndrome. ${ }^{19}$ The reported case had significant hair- and skin involvement with woolly hair and a pemphigous-like skin disorder. Interestingly, our patient with a similar glycine to arginine substitution (p.G2056R+p.G2056R) in a homolog region located in the A domain, only showed mild cutaneous abnormalities and no woolly hair. The C-terminal part of desmoplakin consists of three plakin repeat domains each composed of four and a half copy of a unique 38 amino acid repeat motif. Functional evidence suggests that all three domains have similar binding properties to the intermediate filaments. ${ }^{28}$ The variable phenotype between the two homozygous missense mutation carriers is therefore not likely to be caused by a weaker binding of the intermediate filaments to the A domain. Our patient had significant left ventricular involvement consistent with two out of three reports on homozygous DSP mutation carriers. ${ }^{19-21}$ In addition to homozygous mutations, compound heterozygous and dominant DSP mutations with variable degrees of cardiac and cutaneous involvement have been reported. ${ }^{29}$

The present study furthermore aimed at investigating large genomic rearrangements. Only a single report from the Netherlands has implicated large genomic deletions in the pathogenesis of ARVC with a diagnostic yield below one percent. ${ }^{30}$ However, only 26 patients out of the 120 patients screened in this study fulfilled Task Force criteria. ${ }^{30}$ Our results are in keeping with the Dutch study, as no rearrangements were identified in our cohort. Although a substantial part of the reported desmosomal mutations are truncating with haploinsufficiency as the proposed molecular mechanism, large genomic deletions does not seem to be a common cause of ARVC. In contrast to this, MLPA analysis of a selected group of long QT syndrome patients showed that $11.5 \%$ of patients had disease-causing large genomic rearrangements. ${ }^{31}$

None of the 10 borderline patients had potentially disease-causing mutations as only two variants of unknown significance (DSC2 p.A897KfsX4 and DSG2 p.V920G) were found. This 
finding may be coincidental and reflect the small sample size. The average period of follow-up was long in these patients (data not shown) suggesting that time-dependent reduced expressivity is not the case, and that these patients may represent phenocopies.

The following limitations apply to this study: cohort size, referral bias to tertiary center, a limited number of family members available for evaluation, issues related to mutation analysis on DNA extracted from paraffin-embedded tissue, and the lack of functional tests available for verification of the disease causing effect of identified mutations. Furthermore, the MLPA kit had a limited number of probes and the sensitivity of the kit may not be $100 \%$. Due to few patients carrying more than one mutation and unclear pathogeneity of a number of the identified mutations no meaningful statistical genotype-phenotype comparisons between single and double mutation carriers were possible. Lastly, due to the anonymous nature of our control population no systematic evaluation for ARVC was possible and it cannot be definitively ruled out that some controls had silent disease.

In conclusion, $33 \%$ of the patients in this Danish ARVC cohort had desmosomal mutations with a wide mutation spectrum and a substantial proportion of patients carried more than one mutation. The phenotype associated with the double carrier status was variable. Our data clearly support comprehensive mutation screening beyond the first encountered mutation, while routine screening for large genomic rearrangements does not seem indicated. 


\section{Acknowledgements}

We thank all participating patients and their families. We also thank Claus B. Andersen for providing the photomicrograph.

\section{Funding}

This work was supported by grants from The Danish National Arrhythmia Research Foundation Centre for Cardiac Arrhythmia (DARC), Danish Cardiovascular Research Academy (DaCRA), The Research Council at the Heart Centre, Rigshospitalet, The Villadsen Family Foundation, Brødrene Hartmanns Foundation, and The John and Birthe Meyer Foundation.

\section{Competing interests}

None.

\section{$\underline{\text { Patient consent }}$}

Obtained. 
References

1. McKenna WJ, Thiene G, Nava A, Fontaliran F, Blomstrom-Lundqvist C, Fontaine G, Camerini F. Diagnosis of arrhythmogenic right ventricular dysplasia/cardiomyopathy. Task Force of the Working Group Myocardial and Pericardial Disease of the European Society of Cardiology and of the Scientific Council on Cardiomyopathies of the International Society and Federation of Cardiology. Br Heart J 1994;71:215-218.

2. Marcus FI, McKenna WJ, Sherrill D, Basso C, Bauce B, Bluemke DA, Calkins H, Corrado D, Cox MG, Daubert JP, Fontaine G, Gear K, Hauer R, Nava A, Picard MH, Protonotarios N, Saffitz JE, Sanborn DM, Steinberg JS, Tandri H, Thiene G, Towbin JA, Tsatsopoulou A, Wichter T, Zareba W. Diagnosis of arrhythmogenic right ventricular cardiomyopathy/dysplasia: Proposed Modification of the Task Force Criteria. Eur Heart J 2010;Epub Feb 19.

3. Hamid MS, Norman M, Quraishi A, Firoozi S, Thaman R, Gimeno JR, Sachdev B, Rowland E, Elliott PM, McKenna WJ. Prospective evaluation of relatives for familial arrhythmogenic right ventricular cardiomyopathy/dysplasia reveals a need to broaden diagnostic criteria. J Am Coll Cardiol 2002;40:1445-1450.

4. Syrris P, Ward D, Evans A, Asimaki A, Gandjbakhch E, Sen-Chowdhry S, McKenna WJ. Arrhythmogenic right ventricular dysplasia/cardiomyopathy associated with mutations in the desmosomal gene desmocollin-2. Am J Hum Genet 2006;79:978-984.

5. Simpson MA, Mansour S, Ahnood D, Kalidas K, Patton MA, McKenna WJ, Behr ER, Crosby AH. Homozygous Mutation of Desmocollin-2 in Arrhythmogenic Right Ventricular 
Cardiomyopathy with Mild Palmoplantar Keratoderma and Woolly Hair. Cardiology 2008;113:28-34.

6. Pilichou K, Nava A, Basso C, Beffagna G, Bauce B, Lorenzon A, Frigo G, Vettori A, Valente M, Towbin J, Thiene G, Danieli GA, Rampazzo A. Mutations in desmoglein-2 gene are associated with arrhythmogenic right ventricular cardiomyopathy. Circulation 2006;113:11711179.

7. Syrris P, Ward D, Asimaki A, Evans A, Sen-Chowdhry S, Hughes SE, McKenna WJ. Desmoglein-2 mutations in arrhythmogenic right ventricular cardiomyopathy: a genotypephenotype characterization of familial disease. Eur Heart J 2007;28:581-588.

8. Bhuiyan ZA, Jongbloed JDH, van der Smagt J, Lombardi PM, Wiesfeld AC, Nelen M, Schouten M, Jongbloed R, Cox MG, van Wolferen M, Rodriguez LM, van Gelder IC, Bikker H, Suurmeijer AJH, van den Berg M, Mannens MAM, Hauer RNW, Wilde AMA, van Tintelen JP. Desmoglein-2 and Desmocollin-2 Mutations in Dutch Arrhythmogenic Right Ventricular Dysplasia/Cardiomyopathy Patients: Results from a Multicenter Study. Circ Cardiovasc Genet 2009;2:418-427.

9. Awad MM, Dalal D, Cho E, mat-Alarcon N, James C, Tichnell C, Tucker A, Russell SD, Bluemke DA, Dietz HC, Calkins H, Judge DP. DSG2 mutations contribute to arrhythmogenic right ventricular dysplasia/cardiomyopathy. Am J Hum Genet 2006;79:136-142.

10. Rampazzo A, Nava A, Malacrida S, Beffagna G, Bauce B, Rossi V, Zimbello R, Simionati B, Basso C, Thiene G, Towbin JA, Danieli GA. Mutation in human desmoplakin domain binding to plakoglobin causes a dominant form of arrhythmogenic right ventricular cardiomyopathy. Am J Hum Genet 2002;71:1200-1206. 
11. Yang Z, Bowles NE, Scherer SE, Taylor MD, Kearney DL, Ge S, Nadvoretskiy VV, DeFreitas G, Carabello B, Brandon LI, Godsel LM, Green KJ, Saffitz JE, Li H, Danieli GA, Calkins H, Marcus F, Towbin JA. Desmosomal dysfunction due to mutations in desmoplakin causes arrhythmogenic right ventricular dysplasia/cardiomyopathy. Circ Res 2006;99:646655.

12. McKoy G, Protonotarios N, Crosby A, Tsatsopoulou A, Anastasakis A, Coonar A, Norman M, Baboonian C, Jeffery S, McKenna WJ. Identification of a deletion in plakoglobin in arrhythmogenic right ventricular cardiomyopathy with palmoplantar keratoderma and woolly hair (Naxos disease). Lancet 2000;355:2119-2124.

13. Asimaki A, Syrris P, Wichter T, Matthias P, Saffitz JE, McKenna WJ. A novel dominant mutation in plakoglobin causes arrhythmogenic right ventricular cardiomyopathy. Am J Hum Genet 2007;81:964-973.

14. Gerull B, Heuser A, Wichter T, Paul M, Basson CT, McDermott DA, Lerman BB, Markowitz SM, Ellinor PT, MacRae CA, Peters S, Grossmann KS, Drenckhahn J, Michely B, SasseKlaassen S, Birchmeier W, Dietz R, Breithardt G, Schulze-Bahr E, Thierfelder L. Mutations in the desmosomal protein plakophilin-2 are common in arrhythmogenic right ventricular cardiomyopathy. Nat Genet 2004;36:1162-1164.

15. van Tintelen JP, Entius MM, Bhuiyan ZA, Jongbloed R, Wiesfeld AC, Wilde AA, van der SJ, Boven LG, Mannens MM, van L, I, Hofstra RM, Otterspoor LC, Doevendans PA, Rodriguez LM, van G, I, Hauer RN. Plakophilin-2 mutations are the major determinant of familial arrhythmogenic right ventricular dysplasia/cardiomyopathy. Circulation 2006;113:1650-1658. 
16. Christensen AH, Benn M, Tybjaerg-Hansen A, Haunso S, Svendsen JH. Missense Variants in Plakophilin-2 in Arrhythmogenic Right Ventricular Cardiomyopathy Patients - DiseaseCausing or Innocent Bystanders? Cardiology 2009;115:148-154.

17. Beffagna G, Occhi G, Nava A, Vitiello L, Ditadi A, Basso C, Bauce B, Carraro G, Thiene G, Towbin JA, Danieli GA, Rampazzo A. Regulatory mutations in transforming growth factorbeta3 gene cause arrhythmogenic right ventricular cardiomyopathy type 1. Cardiovasc Res 2005;65:366-373.

18. Merner ND, Hodgkinson KA, Haywood AF, Connors S, French VM, Drenckhahn JD, Kupprion C, Ramadanova K, Thierfelder L, McKenna W, Gallagher B, Morris-Larkin L, Bassett AS, Parfrey PS, Young TL. Arrhythmogenic right ventricular cardiomyopathy type 5 is a fully penetrant, lethal arrhythmic disorder caused by a missense mutation in the TMEM43 gene. Am J Hum Genet 2008;82:809-821.

19. Alcalai R, Metzger S, Rosenheck S, Meiner V, Chajek-Shaul T. A recessive mutation in desmoplakin causes arrhythmogenic right ventricular dysplasia, skin disorder, and woolly hair. J Am Coll Cardiol 2003;42:319-327.

20. Uzumcu A, Norgett EE, Dindar A, Uyguner O, Nisli K, Kayserili H, Sahin SE, Dupont E, Severs NJ, Leigh IM, Yuksel-Apak M, Kelsell DP, Wollnik B. Loss of desmoplakin isoform I causes early onset cardiomyopathy and heart failure in a Naxos-like syndrome. J Med Genet 2006;43:e5.

21. Norgett EE, Hatsell SJ, Carvajal-Huerta L, Cabezas JC, Common J, Purkis PE, Whittock N, Leigh IM, Stevens HP, Kelsell DP. Recessive mutation in desmoplakin disrupts desmoplakinintermediate filament interactions and causes dilated cardiomyopathy, woolly hair and keratoderma. Hum Mol Genet 2000;9:2761-2766. 
22. Lahtinen AM, Lehtonen A, Kaartinen M, Toivonen L, Swan H, Widen E, Lehtonen E, Lehto VP, Kontula K. Plakophilin-2 missense mutations in arrhythmogenic right ventricular cardiomyopathy. Int J Cardiol 2008;126:92-100.

23. Heuser A, Plovie ER, Ellinor PT, Grossmann KS, Shin JT, Wichter T, Basson CT, Lerman BB, Sasse-Klaassen S, Thierfelder L, MacRae CA, Gerull B. Mutant desmocollin-2 causes arrhythmogenic right ventricular cardiomyopathy. Am J Hum Genet 2006;79:1081-1088.

24. den Haan AD, Tan BY, Zikusoka MN, Lladó LI, Jain R, Daly A, Tichnell C, James C, Alarcon NA, Abraham T, Russell SD, Bluemke DA, Calkins H, Dalal D, Judge DP. Comprehensive Desmosome Mutation Analysis in North Americans with Arrhythmogenic Right Ventricular Dysplasia/Cardiomyopathy. Circ Cardiovasc Genet 2009;2:428-435.

25. Ly S, Marcus FI, Xu T, Towbin JA. A woman with incidental findings of ventricular aneurysms and a desmosomal cardiomyopathy. Heart Rhythm 2008;5:1455-1457.

26. Bauce B, Nava A, Beffagna G, Basso C, Lorenzon A, Smaniotto G, De BM, Rigato I, Mazzotti E, Steriotis A, Marra MP, Towbin JA, Thiene G, Danieli GA, Rampazzo A. Multiple mutations in desmosomal proteins encoding genes in arrhythmogenic right ventricular cardiomyopathy/dysplasia. Heart Rhythm 2010;7:22-29.

27. Poelzing S, Forleo C, Samodell M, Dudash L, Sorrentino S, Anaclerio M, Troccoli R, Iacoviello M, Romito R, Guida P, Chahine M, Pitzalis M, Deschenes I. SCN5A polymorphism restores trafficking of a Brugada syndrome mutation on a separate gene. Circulation 2006;114:368-376. 
28. Choi HJ, Park-Snyder S, Pascoe LT, Green KJ, Weis WI. Structures of two intermediate filament-binding fragments of desmoplakin reveal a unique repeat motif structure. Nat Struct Biol 2002;9:612-620.

29. Asimaki A, Syrris P, Ward D, Guereta LG, Saffitz JE, McKenna WJ. Unique epidermolytic bullous dermatosis with associated lethal cardiomyopathy related to novel desmoplakin mutations. J Cutan Pathol 2009;36:553-559.

30. van der Smagt J, Cox MG, Nelen MR, van Tintelen JP, Entius MM, Wiesfeld AC, van Gelder IC, de Jong GJ, Doevendans PA, Hauer RN. Large Genomic Deletions in Plakophilin2 are a Rare Cause of ARVD/C and ARVD/C-like Disease. Circulation 2007;116(Suppl):604.

31. Eddy CA, MacCormick JM, Chung SK, Crawford JR, Love DR, Rees MI, Skinner JR, Shelling AN. Identification of large gene deletions and duplications in KCNQ1 and KCNH2 in patients with long QT syndrome. Heart Rhythm 2008;5:1275-1281.

"The Corresponding Author has the right to grant on behalf of all authors and does grant on behalf of all authors, an exclusive licence (or non exclusive for government employees) on a worldwide basis to the BMJ Publishing Group Ltd to permit this article (if accepted) to be published in JMG and any other BMJPGL products and sublicences such use and exploit all subsidiary rights, as set out in our licence (http://group.bmj.com/products/journals/instructions-for-authors/licence-forms)." 


\section{$\underline{\text { Figure legends }}$}

Figure 1. Pedigrees of families with digenic or compound inheritance. Women are illustrated by circles and men by squares. Filling in the circles/squares indicates fulfilment of ARVC criteria (black), modified criteria (grey), unaffected (white), or unknown (question mark). Probands are marked with an arrowhead. Deceased family members are illustrated with diagonal lines. Below the gender symbol the molecular genetic finding is listed: Mutation (gene name and position), wild type (wt) or untested (question mark). An asterix indicates obligate carrier status. Bottom numbers are the generation and individual numbers.

Figure 2. A) ECG from individual II:8 (Family A), who had significant left ventricular involvement, showing left axis deviation and negative T-waves in V2-V6, I-III and AVF. B) Myocardial tissue from the autopsy of individual III:4 (Family A) showing fibrofatty replacements. C) Electropherogram from individual II:6 (Family A).

Figure 3. A) Pedigree of the family (Family H) carrying the homozygous DSP p.G2056R mutation. B) Picture of the face and hair of the proband (individual IV:1) showing curly, but not woolly, hair. C) Picture of the hand of the proband showing palmar keratoderma. D) Electropherogram from the proband. Written informed consent was given for the publication of these images. 
Table 1. Clinical characteristics of the cohort according to the 1994 Task Force criteria.

\begin{tabular}{llcc}
\hline & & ARVC group & Borderline group \\
\hline Age at symptom onset, years (range) & & $35(2-62)$ & $36(12-52)$ \\
Gender, men & & $32 / 55(58 \%)$ & $6 / 10(60 \%)$ \\
Reduced left ventricular function & & $10 / 55(18 \%)$ & $2 / 10(20 \%)$ \\
Family history & Major & $4 / 55(7 \%)$ & $0 / 10(0 \%)$ \\
& Minor & $8 / 55(15 \%)$ & $1 / 10(10 \%)$ \\
Abnormal depolarization & Major & $18 / 55(33 \%)$ & $1 / 10(10 \%)$ \\
& Minor & $17 / 55(31 \%)$ & $4 / 10(40 \%)$ \\
Abnormal repolarization & Minor & $25 / 55(46 \%)$ & $1 / 10(10 \%)$ \\
Arrhythmia & Minor & $49 / 55(89 \%)$ & $10 / 10(100 \%)$ \\
Structural or functional abnormality of & Major & $11 / 55(20 \%)$ & $1 / 10(10 \%)$ \\
the right ventricle & Minor & $29 / 55(53 \%)$ & $3 / 10(30 \%)$ \\
Tissue characteristics & Major & $31 / 55(56 \%)$ & $3 / 10(30 \%)$ \\
\hline
\end{tabular}


Table 2. Overview of the mutations.

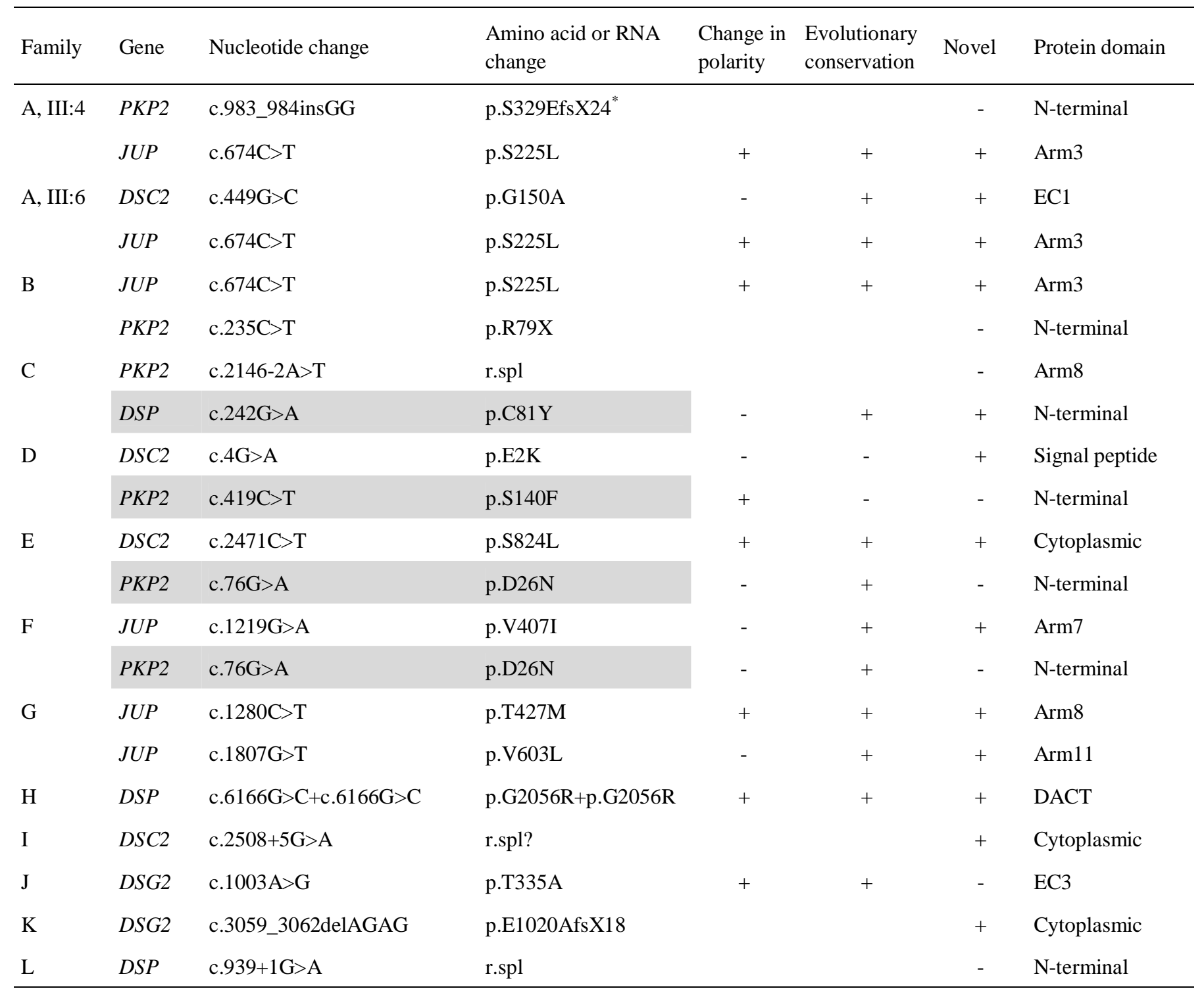

Arm: Armadillo repeat; DACT: Domain A, C-terminal; EC: Extracellular repeat. Variants present in control population are in shaded grey. * Reported as PKP2 E329fsX352 due to alternative nomenclature. 
Table 3. Clinical characteristics of mutation carriers.

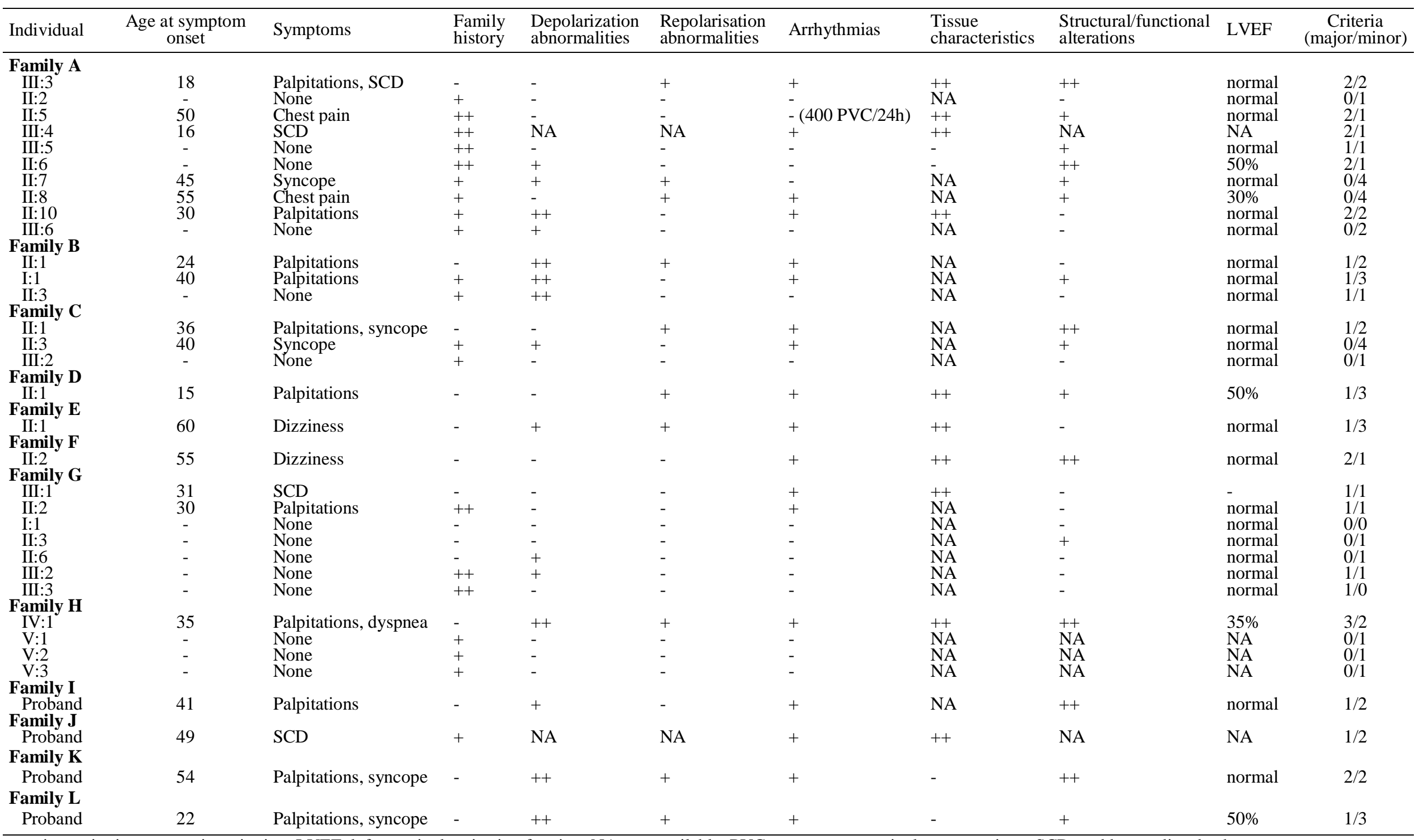

+: minor criterion; ++: major criterion, LVEF: left ventricular ejection fraction; NA: not available; PVC: premature ventricular contractions; SCD: sudden cardiac death. 
A

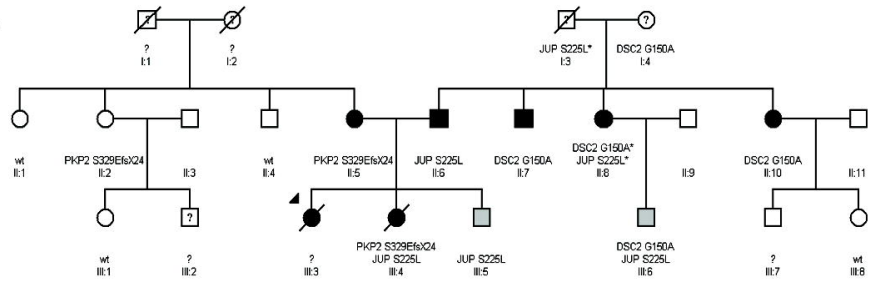

B

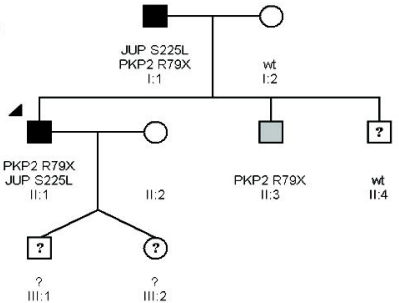

D

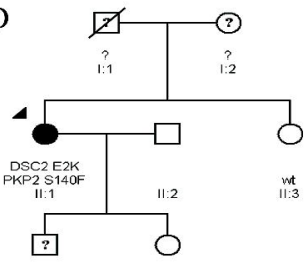

F

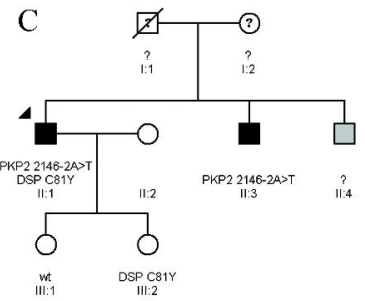

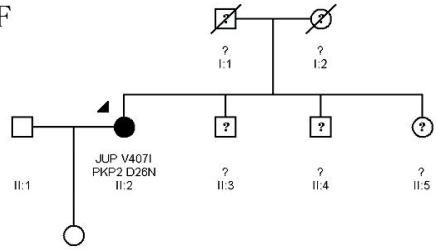

?

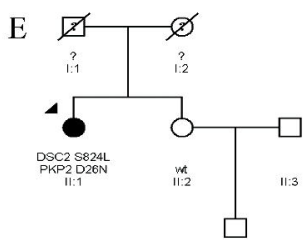

III: 1

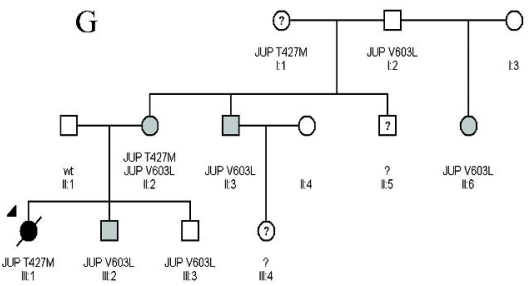


Alo mal al $25 \cdot \operatorname{mat} / 8 \mathrm{ffl}$ tet $35 \mathrm{~Hz}$

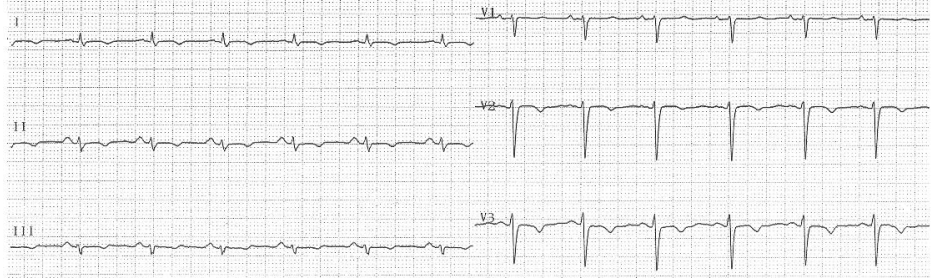

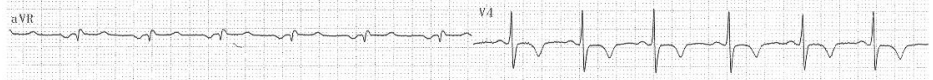

a\%

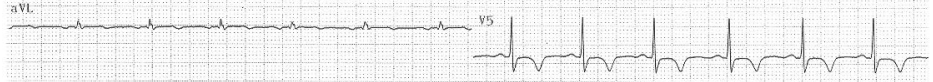

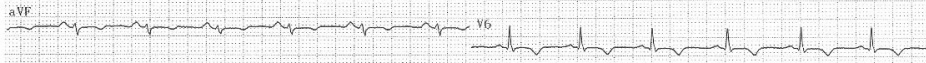

B

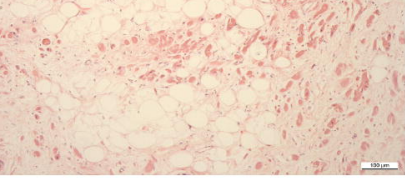

C

JUP normal

$J U P 674 \mathrm{C}>\mathrm{T}$

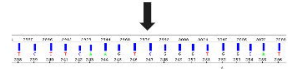

11

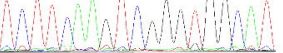

I" ! I I ! ! I ! I

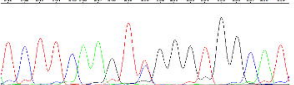



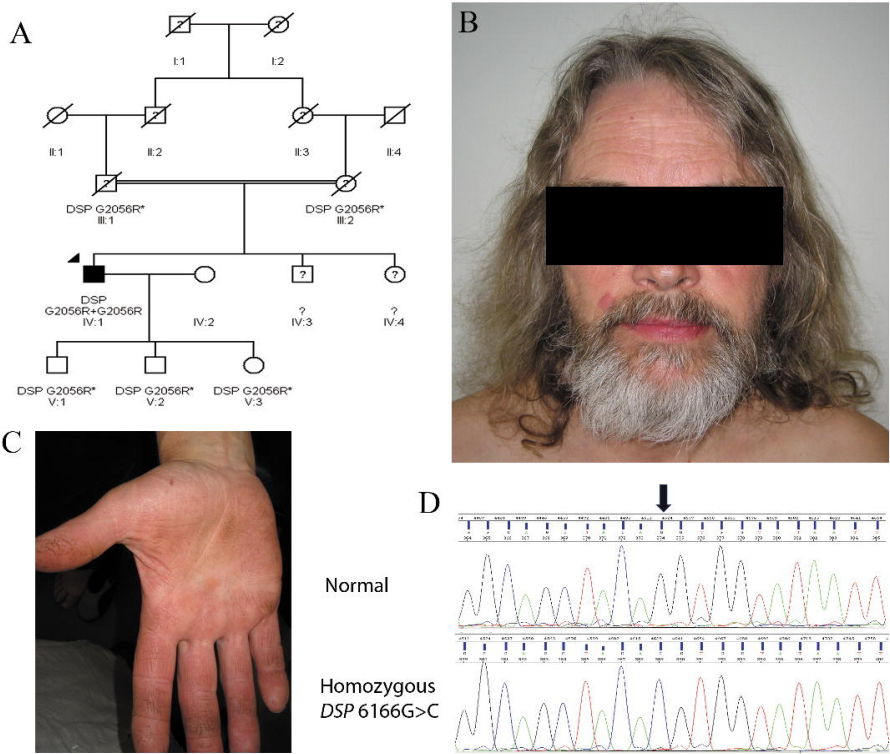

D

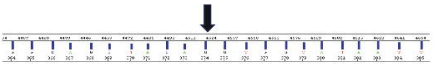

Normal

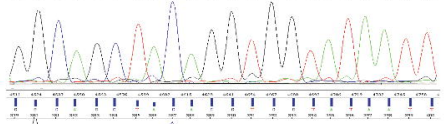

Homozygous DSP 6166G $>C$

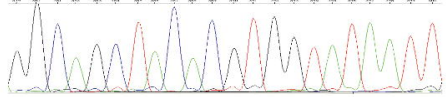

